\title{
perifèria
}

Número 9, diciembre 2008

www.periferia. name

\section{A través de sus ojos. Etnografía visual en un centro educativo de la periferia urbana}

\author{
Paula González Granados ${ }^{1}$ - Dep. d'Antropologia, Filosofia i Treball Social \\ (URV, Tarragona)
}

\section{Resumen}

La fotografía, como herramienta metodológica, permite trabajar en colaboración con los informantes, en un proceso de construcción y deconstrucción de significados y una búsqueda conjunta de maneras de representación a través de la misma. Partiendo de la convicción de que la fotografía es una herramienta de comunicación, a través del cual nos representamos socialmente, sugiero llevar a cabo una metodología en que los informantes tomen las cámaras de fotos y, compartiendo un proceso de trabajo con la investigadora, vayan extrayendo aquellos momentos o lugares que les parecen más significativos de su vida y de su entorno. Esta ha sido la metodología utilizada en el campo de investigación, una Unidad de Escolarización Compartida, recurso educativo dirigido a jóvenes expulsados de sus centros educativos de referencia. Este centro se sitúa en un barrio periférico de la ciudad de Tarragona, construido a raíz del impulso de la industria petroquímica.

Palabras clave: fotografía; representación visual; segregación urbana; adolescencia.

\begin{abstract}
Photography as a methodological tool allows working in collaboration with the informants in a process of meaning construction and deconstruction and in a joint search for ways of representation through this tool. From the conviction that photography is a communication tool with which we represent ourselves socially, I suggest a methodology in which the informants take the photographic camera and extract the more significant moments and places of their life and their environment in a shared working process with the researcher. This has been the methodology used in the field research, a Shared Schooling Unity, educational resource addressed to youngsters expelled from their reference educational centers. This center is located in the outskirts of Tarragona, an area built mainly due to the development of the petrochemical industry.
\end{abstract}

\footnotetext{
${ }^{1}$ Enviar correspondencia a: paula_espacio@hotmail.com
} 


\section{perifèria}

Número 9, diciembre 2008

www.periferia.name

Key words: Photography; visual representation; urban segregation; adolescence.

\section{Introducción}

Partimos del hecho de que la mirada es un sentido que se construye culturalmente, y por ello es un acto subjetivo, manipulable. La manera en que se construye visualmente una fotografía (la composición), o cómo se estructura temporal y visualmente una película, es socialmente aceptada porque la entendemos, responde a nuestras expectativas, a nuestra forma de mirar. De esta modo, cuando las imágenes "hablan" de nosotros, nos describen, buscamos una manera socialmente aceptable de aparecer en ellas, o de retratar nuestro ambiente. Cuando vamos de viaje equipados con una cámara, sabemos cómo queremos retratar éste o aquel monumento o escena, cómo nos colocamos (o colocamos a los demás), cómo estructuramos ese momento. Cuando subimos a algún portal de Internet (pensemos en facebook ${ }^{2}$, por ejemplo) una fotografía queremos que lo que se muestre en ésta retrate de alguna manera lo que somos, o queremos ser. Ejemplos de la importante significación de la imagen fija reproducida en nuestras vidas hay muchos, y es socialmente común poseer una serie de ellas que guardan momentos congelados que sentimos como propios (pensemos, por ejemplo, en las fotografías familiares, o en las de los amigos) e incluso las distribuimos e intercambiamos con otras personas.

Por ello, y como manera de captar una parte de la cosmovisión de una persona o grupo, las fotografías pueden tender puentes para la comprensión antropológica y para mejorar la relación que establecemos con los informantes. Al igual que compartir una entrevista con alguien puede ser un acto íntimo de comprensión de aspectos concretos de la vida individual de esa persona (lo que nos permite emitir teorías sobre su grupo de referencia) que posibilita la obtención de datos clave para la investigación, el hecho de trabajar con fotografías, ya sea las que están ahí, o de

\footnotetext{
2 Servidor de Internet en que existe la posibilidad (entre otras muchas opciones) de que los usuarios cuelguen sus fotografías y las compartan con otros, a los que se llama "amigos".
} 


\section{perifèria}

Número 9, diciembre 2008

www. periferia.name

nueva creación, posibilita, e incluso nos permite, profundizar en aquellos temas que nos interesan. Porque ante todo hay que decir que fotografiar no es un acto objetivo. De esto se deduce que lo que obtenemos de este acto, la imagen final, es cultural e intencionadamente construida. Determinado tipo de fotografía (por ejemplo, la de reportaje) aparece ante nosotros como si no hubiese mediado ningún elemento entre la cámara y la escena retratada. Pero no debemos olvidar nunca que tras ese aparato mecánico hay una persona que escoge el encuadre, el momento a fotografiar. Que se haya generalizado un determinado tipo de fotografía sobre los países más pobres, por ejemplo, no es una casualidad, y no debemos olvidar que tras esa imagen hay un punto de vista, un posicionamiento ante el mundo, y una conciencia clara de que esa imagen será mostrada a un público determinado. Es, al fin y al cabo, un medio que incluye todos los elementos del acto comunicativo, es decir, que existe aquel que emite la información y aquel que la recibe, perteneciendo ambos actores a un contexto determinado. Entender qué se quiere expresar con esa información es la finalidad del proyecto que llevo a cabo.

Con esta metodología y estos presupuestos de base me he acercado a un grupo de adolescentes que viven en una barriada periférica de Tarragona, y lo he hecho adentrándome en su contexto educativo de referencia (de ambos contexto, urbano y educativo, trataré inmediatamente). Mi intención con este primer acercamiento de establecer una teoría sobre la segregación urbana en la sociedad contemporánea, y las consecuencias que ésta provoca en personas del perfil de estos informantes. 


\section{perifèria}

Número 9, diciembre 2008

www.periferia.name

\section{Contextualización}

\subsection{Contexto urbano}

La denominada Zona Ponent en Tarragona engloba diferentes barrios ${ }^{3}$, creados a partir del crecimiento industrial de la ciudad, sobretodo del sector petroquímico, por una parte, y el turístico, por otra. Este crecimiento acelerado en un período de tiempo breve, unos cuarenta años, supuso un aumento de la población muy significativo, con lo que esto conlleva de demanda de vivienda por parte de las poblaciones recién llegadas. Las zonas que rodeaban a la ciudad de Tarragona, terrenos agrícolas de propiedad privada, fueron adquiridas por particulares y por el ayuntamiento para comenzar a construir la zona a la que actualmente nos referimos, cercana a los polígonos industriales de nueva creación.

Ya antes de que se produjera el boom industrial y turístico en la ciudad de Tarragona, había comenzado a darse un movimiento migratorio generalizado, del sur al norte de la península, en el que personas de zonas deprimidas e industrialmente subdesarrolladas, huían de la miseria y de la falta de oportunidades en sus comunidades de origen. Cataluña sería entonces una de las zonas receptoras de esas poblaciones, lo que influiría enormemente en su desarrollo futuro. De esta manera, no podemos entender el crecimiento de Tarragona como un movimiento ordenado en que primero se implantan las industrias para dejar paso a la población en busca de trabajo, sino que observamos una primera llegada de personas provenientes en su mayoría de Andalucía y Extremadura, que en muchos casos provienen de zonas concretas e incluso del mismo pueblo, y un movimiento cada vez más elevado de poblaciones que van llegando a medida que se implantan en el territorio las empresas más importantes, y que mayor cantidad de fuerza de trabajo necesitan.

\footnotetext{
${ }^{3}$ La formación de la zona Ponent ha sido históricamente escalonada y diversificada, con lo que se han ido formando los diferentes barrios que existen hoy en día. Encontramos bloques construidos a partir de la iniciativa de las propias empresas, que respondían a la necesidad de vivienda de sus trabajadores; otros de iniciativa privada, potenciados por empresas inmobiliarias; también encontramos el fenómeno de la autoconstrucción de viviendas; y, finalmente, la iniciativa del gobierno, con la promoción de vivienda social, concentrada en su mayoría en esta zona de la ciudad.
} 


\section{perifèria}

Número 9, diciembre 2008

\section{www.periferia.name}

Podríamos pensar que un aumento tal de la población vino acompañado por una respuesta efectiva por parte de las autoridades políticas, en lo que a instalación de viviendas y servicios se refiere. Pero esto no fue así en el caso de Tarragona. Ya existían en la ciudad problemas con determinadas zonas, como la parte histórica (denominada "Part Alta") donde las condiciones de salubridad y habitabilidad de las viviendas no eran ni mucho menos las adecuadas. ¿Cómo entonces iba a solucionarse el problema de la vivienda de cara a un aumento de la población que llegó a doblar la que existía hasta ese momento? Los comienzos de este crecimiento fueron entonces problemáticos para las poblaciones que llegaron a la ciudad en busca de mejores condiciones de vida.

En la historia escrita de todos estos barrios encontramos una pésima planificación urbanística, un aislamiento acentuado por la falta de transportes eficientes, una falta de servicios y recursos básicos (sanitarios, educativos) y la presencia de situaciones sociales precarias que acentúan el aislamiento con respecto a la Tarragona central ${ }^{4}$. Esto provoca una estigmatización que ha ido acrecentándose en el imaginario de los habitantes de Tarragona, lo que se traduce en una ciudad formada por diferentes zonas ${ }^{5}$, que se desarrollan independientemente las unas de las otras, y eso que hablamos de una población relativamente reducida (unos 120.000 habitantes). Esta estigmatización, lejos de producir poblaciones subalternas sin capacidad de reacción, hizo crecer en las primeras décadas de asentamiento poblacional un movimiento asociativo fuerte y variado que reivindicó los servicios necesarios para poder llevar una vida digna ${ }^{6}$.

Es este un contexto urbano históricamente segregado, en el que se observa una separación clara entre centro y periferia, donde el centro detenta una mejor infraestructura urbana y menores índices de pobreza y conflicto social. Este crecimiento segregado de la ciudad supone una separación que se instala

\footnotetext{
${ }^{4}$ Con esta denominación me refiero a la parte de la ciudad que ya existía antes del crecimiento al que hacemos referencia, y que engloba el casco antiguo y la zona adyacente (ramblas, fachada marítima, puerto de pescadores)

${ }^{5}$ Un historiador de la ciudad, Baixeras i Sastre, la ha definido como "ciudad constelada", lo que me parece una descripción muy adecuada en el caso de Tarragona.

${ }^{6}$ Para un análisis de estos movimientos asociativos, hasta los años 80, ver Pujadas y Bardají (1987)
} 


\section{perifèria}

Número 9, diciembre 2008

\section{www.periferia.name}

igualmente en el imaginario de las personas que viven en una y otra parte de la ciudad. A partir de aquí se plantean diferentes preguntas para el análisis. En este caso, he centrado el estudio en la cosmovisión de un grupo de adolescentes de los barrios de Ponent, doblemente segregados por pertenecer a la categoría social de "problemáticos" y que desarrollan su actividad educativa en un centro, denominado UEC, que paso a describir brevemente en el siguiente punto.

\subsection{El entorno educativo}

Las Unidades de Educación Compartida son centros educativos que están destinados a atender a aquellos alumnos que "fracasan" en el ámbito educativo normalizado y que según la ley han de estar escolarizados hasta los 16 años ${ }^{7}$. En Tarragona hay tres centros de este tipo, todos ellos ubicados en los barrios de Ponent.

En el caso del centro en que he realizado el trabajo de campo (denominado UECPonent) encontramos una instalación separada del centro de referencia de los alumnos, situada de cara a la carretera, con deficiencias claras para desarrollar una actividad educativa normalizada (entre otras, no disponen de patio, no hay calefacción, ni fotocopiadora). En este centro se imparten las asignaturas corrientes, además de una serie de talleres dirigidos a la inserción en el ámbito profesional (jardinería, cocina, pintura), y otras actividades paralelas (por ejemplo el taller de fotografía en el que me integré como profesora). El número de plazas es 14, estando todas cubiertas en la época en que realicé el trabajo de campo, aunque regularmente acudían ocho alumnos ${ }^{8}$.

\footnotetext{
${ }^{7}$ Norma establecida por la ley 1/1990 de 3 de Octubre de Ordenación General del Sistema Educativo.

${ }^{8}$ Muchos de estos alumnos presentan un absentismo continuado, lo que supone una de las causas más frecuentes para que sean expulsados del instituto, y derivados a una UEC. Una vez aquí, el absentismo no siempre desaparece, pues es un fenómeno que obedece a diferentes situaciones que tienen que ver con el contexto social del alumno. Según el Diagnóstico Comunitario de la Zona Ponent (2004) el absentismo en esta zona se relaciona con diferentes situaciones, que tienen que ver con la estructura familiar, la precariedad económica, los modelos culturales, la desvalorización de la escuela. Desde la UEC se hace un seguimiento mucho más cercano de cada situación, y se dan casos de compromiso por parte del alumno y la familia de que éste acudirá a las clases.
} 


\section{perifèria}

Número 9, diciembre 2008

\section{www.periferia.name}

Según un documento generado en un seminario de profesores de este tipo de centros $^{9}$, los alumnos UEC presentan el siguiente perfil:

Alumnos que presentan necesidades educativas especiales derivadas de la inadaptación social al medio escolar, aquellos que, además de un retraso en el aprendizaje, presentan de forma reiterada:

- Desajustes conductuales graves que se manifiestan en situaciones de agresividad o violencia que ponen en peligro su convivencia en el centro

- Absentismo injustificado, rechazo escolar, existencia de conductas predelictivas...

Según el director de la UEC Ponent, en referencia al absentismo de estos alumnos,

(...) por un lado están desmotivados en el sentido que no les interesa o porque están frustrados al no poder alcanzar los objetivos educativos. También por desmotivaciones personales o situaciones familiares que hacen que se queden en casa, o que estén en la calle. Porque no todo alumno absentista está en la calle, a veces las familias lo permiten. Entonces ¿para qué van a ir a clase?.

Además, apuntaba en la entrevista, desde el instituto se tarda mucho en avisar de estos casos, lo que provoca que no se detecten a tiempo y puedan convertirse en crónicos.

Me interesó saber hasta qué punto la educación de estos alumnos es compartida, tal como se expresa en la denominación de los centros. El director me respondía lo siguiente:

Es triste que más que compartido es terminal, desde el punto de vista del instituto, nos quitamos este alumno, y ya se harán cargo. A veces sí que nos dan palmaditas en la espalda, que qué bien que lo hacemos, pero a veces tienes la sensación de que te traen un paquete, pero es una persona, aquí lo tienes, y bueno, buscas el libro de instrucciones y no hay.

Tal como está pensado actualmente el servicio, de manera terminal más que compartida, cuesta cumplir objetivos de normalización de estos alumnos en su relación con el ámbito educativo. La UEC, tal como está planteada actualmente,

\footnotetext{
${ }^{9}$ Les Unitats d'Escolarització Compartida (UEC): Un recurs extraordinari per l'atenció a la diversitat en I'ESO (curs 2000-2001)
} 


\section{perifèria}

Número 9, diciembre 2008

www.periferia. name

segrega a estos alumnos apartándoles de la corriente educativa normalizada. En primer lugar, están separados físicamente, con lo que ello supone de segregación espacial y de sensación de encontrarse en mundos separados con respecto a los alumnos del instituto. En segundo lugar, no disponen de unas instalaciones adecuadas ya que los recursos son extremadamente precarios. Algunos aspectos se han conseguido cambiar, como sustituir el guardia de seguridad por una conserje, con el objetivo de normalizar la vida cotidiana en el centro. También se han establecido una serie de protocolos de derivación de cada alumno, aunque según el director, es "ciencia ficción" que se cumplan tal como ellos desearían.

Al igual que apuntaba en el anterior apartado que Tarragona es una ciudad segregada socialmente, lo que se traduce en una estructura urbana desigual y fragmentada, las UEC suponen la segregación de estos alumnos que se encuentran apartados de la educación normalizada y que son etiquetados como peligrosos, delincuentes y conflictivos. Por ello, y según una de las hipótesis de este estudio, el sistema educativo propicia situaciones de desigualdad a través de la segregación de estos alumnos no deseados.

\section{La entrada al terreno de la investigación}

Cuando me planteé hacer una investigación en los barrios de Ponent, hace ahora más de un año, decidí que me centraría en el universo de la infancia y la adolescencia. Quería saber cómo estas nuevas generaciones vivían en este entorno urbano y cuál era su cosmovisión respecto a él, y a la ciudad de Tarragona en general. Por ello, me puse en contacto con la una fundación que trabaja en los barrios de Ponent, especialmente en uno de ellos, el más degradado, con infancia y adolescencia en riesgo social (según su denominación oficial). Les propuse una serie de talleres de fotografía, explicitando los objetivos de la investigación y pactando con ellos una devolución al acabar el trabajo de campo ${ }^{10}$. Hicieron falta varios meses para poder poner en marcha el proyecto, por razones que tenían que

\footnotetext{
${ }^{10}$ Esta devolución consistía en compartir con ellos los resultados de la investigación, y en realizar una exposición en el barrio, con las fotos de los chavales.
} 


\section{perifèria}

Número 9, diciembre 2008

www.periferia. name

ver con los tiempos de la fundación, la disponibilidad de grupos con quien trabajar y de presupuesto destinado al material necesario para llevar a cabo los talleres.

La metodología que quería utilizar en este proyecto, y el objeto de estudio en sí, demandaba una colaboración con el tejido asociativo de la zona, pues pretendía mantener un contacto continuo con los menores y esto no podía realizarlo por mi cuenta, menos todavía pensando en el tiempo de que disponía para hacer el trabajo de campo. Creí adecuado entonces adentrarme en un entorno educativo reglado, y fue en ese momento cuando surgió la posibilidad de trabajar en la UEC. Era un entorno extraño para mí, pero tras estudiar qué eran estos centros, y realizar primeras entrevistas con el director y los profesores, decidí que sería un contexto interesante para llevar adelante el proyecto.

De esta manera, me incorporé como profesora de fotografía. Pactamos con los profesores una sesión semanal de dos horas con el grupo, y la posibilidad de realizar observaciones y entrevistas fuera de este horario. Desde el principio fui tratada como una más dentro del equipo educativo y esto facilitó enormemente la inmersión en el campo de estudio, ya que tenía facilidad para obtener la información, y podía estar presente en el centro en cualquier momento. El contrapunto se dio a la hora de trabajar con los informantes. Ya desde el primer día me di cuenta que mi rol como profesora suponía que los alumnos me etiquetaran dentro de un imaginario común que, en principio, me situaba como el enemigo. El primer contacto, la primera clase que tuve con ellos, fue un auténtico "baño de realidad" de lo que supone trabajar en este ámbito. Puedes llegar con muy buenas intenciones al campo, pero nunca presuponer cómo será el trabajo allí, porque probablemente te equivoques. Cuando entré a esa clase, con el sonido de la música de los móviles con el volumen a tope, de sillas que se movían, los insultos que se proferían unos a otros, pensé que no sería capaz de hacerlo. El hecho de entrar en un universo nuevo donde era la extraña, la novata, hizo que aquel primer contacto supusiera enfrentarme de golpe con una realidad determinada. Hicieron falta unos dos meses para que unos y otros nos acostumbrásemos a las nuevas dinámicas, nos reconociéramos y pusiéramos a cada cual en el lugar que le tocaba en aquel microcosmos que es la UEC. Desde el primer momento les expliqué lo que estaba 


\section{perifèria}

Número 9, diciembre 2008

\section{www.periferia.name}

haciendo, cuál era uno de mis objetivos. Pero un fallo que cometemos comúnmente los antropólogos (por lo menos eso he observado), es no saber explicar en qué consiste nuestro trabajo de una manera que pueda entender aquel que no está familiarizado con la jerga propia de nuestra disciplina. Fue una de las profesoras la que me ayudó a explicarles esto. Vino a clase y les dijo "mirad, Paula necesita que la ayudéis, quiere hacer un trabajo sobre vosotros. Le interesa cómo vivís, qué hacéis y por qué lo hacéis. Le gustaría que se lo contaseis con vuestras fotografías". Así de fácil.

\section{Metodología}

\subsection{Reflexiones}

Para analizar las representaciones que estos adolescentes tenían sobre sí mismos, y sobre su entorno, decidí ofrecerles la posibilidad de que fueran ellos mismos quienes realizaran fotografías sobre aquello que consideraran significativo de su contexto urbano de referencia. Como no se trataba de darles las cámaras, y olvidarme hasta que me las devolvieran, nos encontrábamos semanalmente en el centro, en una sesión de dos horas. La metodología de trabajo consistía en realizar "paseos fotográficos" por los barrios, a partir de un debate previo sobre qué lugares visitar, y fotografiar. De esta manera, recorreríamos la zona de interés juntos, siendo ellos los que guiaban, pues conocían mucho mejor el entorno. Dándoles este poder de decisión, intentaba limar la relación autoritaria preexistente entre profesora y alumnos, al mismo tiempo que buscaba conocer los lugares que frecuentaban cotidianamente. Además de esta metodología más dirigida, se iban turnando para utilizar las cámaras de una semana a otra. Era consciente de que unos tomarían fotografías, y otros no, pero pretendía que el acto fuera libre, y que saliera con la menor mediación por mi parte. Durante las sesiones, y las entrevistas individuales, tendría la oportunidad de hablar con ellos sobre las fotografías que habían hecho (incluso, como explicaré más adelante, sobre las que no habían hecho). 


\section{perifèria}

Número 9, diciembre 2008

\section{www.periferia.name}

En un trabajo de campo como el que aquí presento, reflexionar sobre la metodología utilizada me resulta inevitable, e imprescindible. En primer lugar, para visualizar los errores cometidos; en segundo lugar, obviamente, para corregirlos en próximas incursiones. Para empezar, reconozco que la introducción al campo ha sido forzada e intrusiva. Los riesgos de insertar el trabajo de campo adoptando un rol ya existente (el de profesora, en este caso) provocan que en más de una ocasión tengas que adaptarte a ese rol, más que adaptarlo a tu forma de trabajar. Este rol asumido conlleva toda una carga simbólica que se reproduce, se crea y recrea en la interacción tanto con los profesores, como con los alumnos. Aceptar esto no me resultó fácil y los primeros meses intenté luchar contra un papel que yo misma había escogido. Es, además, un universo reducido y cotidiano, en que el roce es continuo y las interacciones se multiplican. Por ello, escribir el diario de campo resultó ser una de las más duras tareas, por la densidad de los contactos y la multiplicidad de situaciones, y conflictos.

En cuanto a la introducción de las cámaras fotográficas y la manera de planificar las sesiones con el grupo, también puedo extraer una serie de conclusiones necesarias para entender cómo transcurrieron éstas. En un principio entendí la fotografía más como un fin que como un medio. Esto fue un error. Entendía el trabajo de la siguiente manera: a más fotografías, mejores y más resultados. No me resultó sencillo en un primer momento aplicar los conocimientos teóricos adquiridos en el trabajo de campo. Y es que como dicen los teóricos que han utilizado este tipo de metodología ${ }^{11}$, en el contexto de una investigación en ciencias sociales, los medios audiovisuales sirven para tender puentes de comunicación entre el investigador y los informantes, para captar la "manera de mirar" y a partir de ahí extraer conclusiones sobre los aspectos de esa vida que nos interesan, que vamos conociendo a través de las técnicas de recogida de datos. Veo, entonces, la fotografía como un medio de comunicación, no como un fin en sí misma. Pero no

\footnotetext{
${ }^{11}$ Aunque iré tratando estas teorías a lo largo del texto, existe una autora, Elizabeth Edwards, que desde mi punto de vista expresa en sus trabajos la manera en que quiero entender la imagen en este proyecto. Para ella "la fotografía puede comunicar sobre la cultura, la vida de la gente, experiencias y creencias, no al nivel de descripción superficial pero como metáfora visual que enlaza ese espacio entre lo visible y lo invisible, que comunica o a través del paradigma de la realidad, pero a través de una manera lírica de expresarse" (1999: 58)
} 


\section{perifèria}

Número 9, diciembre 2008

\section{www.periferia.name}

desde el primer momento entendí así el uso de esta técnica. A partir de la reflexión sobre los materiales recogidos, y de la observación de trabajos fotográficos de carácter documental, me he ido dando cuenta de que existe un peligro real de confundir imagen con veracidad. Cierto es que uno de los objetivos educativos de este taller era que los chavales aprendieran a hacer fotografías, que fueran estéticamente, objetivamente, aceptables. Pero el objetivo principal de la investigación no suponía la obtención de unas cuantas imágenes bellas. Se trataba de entender cómo mostraban su mundo a través de las imágenes, ya fuera tras la cámara o delante de ella.

Pero no hay que olvidar que en este caso se planteaban objetivos curriculares, propios de los contenidos reglados del centro. Una de las acciones que llevamos a cabo para cumplirlos, fue conseguir presupuesto para que colaborara en las sesiones un fotógrafo profesional. En principio valoré como muy positivo que éste formara parte activa del proyecto de investigación, es decir, que colaborara en todo el proceso, incluyendo las entrevistas y la reflexión sobre aquello que observábamos en cada sesión. Con el tiempo me di cuenta que este objetivo puede cumplirse si desde el principio has pactado con esa persona que eso sea así. Las cosas, claramente, no suceden dejándose únicamente llevar por la corriente. Pueden suceder, o puede que no. En este caso no pasó. Él venía con el objetivo de enseñarles fotografía y de realizar él mismo sus propias imágenes. De nuevo, no supe transmitir la esencia del proyecto y su participación se adscribió únicamente a esos objetivos curriculares que nombraba al principio. La crítica a esta pretensión inicial podría ser que doy por hecho que cualquiera puede hacer nuestro trabajo, desvalorizándolo de esta manera. Nada más lejos de eso. Pero si de algo podemos aprovecharnos en nuestra disciplina, y estoy plenamente convencida de este punto, es de trabajar estrechamente con las personas y con ellos crear una relación que posibilite que éstas se conviertan en actores activos de la investigación. No es 


\section{perifèria}

Número 9, diciembre 2008

\section{www.periferia.name}

ahora el momento de desarrollar este punto, ya que requeriría de otro artículo aparte, pero uno de mis objetivos en el futuro es trabajar en este sentido ${ }^{12}$.

Aún así, el rol del fotógrafo aportó elementos positivos y de entendimiento en la relación con los informantes y en las observaciones realizadas durante las sesiones de trabajo. Para empezar, estaba el hecho de que es un hombre. Esto es algo que no valoré al principio, pero pronto me di cuenta que este aspecto era altamente significativo. Los informantes, en el contexto que tratamos aquí, han interiorizado un imaginario en el que el papel y los comportamientos de hombres y mujeres están diferenciados y son muy claros. No acude, además, ninguna chica a este centro (como alumna, ya que hay dos profesoras y la conserje). El primer día, cuando me tocó hablar en primer lugar, la atención fue casi nula y no pararon de hablar, o de encender la música de los móviles en todo momento. Hasta alguno de ellos me amenazó diciendo: "No pienso hacer ni una puta foto, ¿entiendes?". Cuando le tocó el turno de hablar al fotógrafo, se hizo el silencio. También hay que decir que utilizó un lenguaje mucho más próximo a ellos y que la ropa que lleva se acerca en cierta manera a la suya (una cierta estética que podríamos enmarcar en la cultura del breakdance, del hip hop). Pero el hecho de que fuera hombre, después de escuchar múltiples comentarios machistas y despectivos hacia las mujeres, fue crucial a la hora de entrar al campo acompañada por él. Por otra parte, el hecho de compartir la carga de trabajo me permitió limar ciertos conflictos que se producían a lo largo del proceso. Si había tenido un problema con alguno de ellos (conflictos relacionados con la difícil relación que se establece entra profesora y alumno), el fotógrafo trataba más con esa persona hasta que las cosas se

\footnotetext{
12 Hay diversas experiencias relacionadas con el uso de los medios audiovisuales de manera colaborativa, tanto en el ámbito académico de las ciencias sociales como en otros ámbitos, como el de la acción social. Encontramos un interesante movimiento de diferentes pueblos indígenas alrededor del mundo, que utilizan la cámara de vídeo como forma de empoderamiento y de conservación de sus costumbres culturales (ver: Ginsburg, Faye. Indigenous Media: Faustian Contract or Glabal Village? In: Cultural Anthropology. Vol.6 no1, 1991, pp 92-112 o - Speed, Shannon: Entre la antropología y los derechos humanos. Hacia una investigación activista y comprometida críticamente. Alteridades (2006) 16 (31) pp 73-85). Otra interesante experiencia es la de Wang, Burris y Yue Ping con mujeres chinas en el ámbito rural (Wang, Caroline, Burris, Mary Ann and Yue Ping, Xiang: Chinese village women as visual anthropologist: a participatory approach to reaching policymakers. Soc. Sci. Med. Vol. 42, No. 10, pp. 1391-1400, 1996)
} 


\section{perifèria}

Número 9, diciembre 2008

www. periferia. name

arreglaban, hasta que pasaba un tiempo prudencial para volver a entablar conversación. Tal como dicen Taylor y Bogdan, el trabajo de campo no está exento del drama que se repite cotidianamente en la vida social ${ }^{13}$. En un contexto como este, en que el roce es diario y se dan situaciones conflictivas por el mismo carácter del centro, todos, profesores y alumnos, tenemos que lidiar para nivelar los conflictos y causar los menores desequilibrios posibles. En un principio pensé que esos conflictos acabarían haciendo que me diese por vencida, por el hecho de dudar constantemente de estar realizando un trabajo válido. Hoy en día, en que continúo con el trabajo de campo en el mismo centro, creo que la experiencia ha servido tanto para obtener información, como para reflexionar sobre la propia naturaleza de la metodología que utilizamos en el proceso continuo que supone el trabajo de campo.

\subsection{Entrevistando en torno a las imágenes}

Mientras que con la observación participante en las sesiones pretendía recoger datos sobre el proceso de toma de fotografías, en las entrevistas mi objetivo principal era recoger las interpretaciones efectuadas a partir de esas fotografías, en boca de sus propios autores. Discursos como "esa foto la hice porque me gusta fumar porros con mis colegas" o "me gustan los autorretratos porque soy yo mismo" expresan diferentes maneras de entender las imágenes, de darles importancia, de mostrarse a uno mismo. La preguntas que me planteo son ¿Qué hace que una persona tome unas u otras fotografías, incluyendo o rechazando determinados momentos? ¿Esta captación de imágenes denota darle importancia a ese momento y no a otros?

En este proyecto, la intención es que la fotografía actúe como medio de expresión que establezca vínculos entre lo que los informantes viven y los discursos sobre esas vivencias. Es también una manera de elicitar aspectos que no salen en las fotos, pero que hacen referencia a ellos. Tomemos como ejemplo el análisis que realicé con el "Negro" de una foto hecha por él mismo. En ella aparecen él y tres

\footnotetext{
${ }^{13}$ Los autores lo expresan de la siguiente manera: "el trabajo de campo está caracterizado por todos los elementos del drama humano que se encuentran en la vida social (...). En el campo, los observadores suelen encontrarse en medios difíciles y delicadas situaciones" (1992: 63)
} 


\section{perifèria}

Número 9, diciembre 2008

\section{www. periferia. name}

amigos en una calle mirando a una alcantarilla. La foto en sí no nos da información sobre lo que ha pasado antes y después, sobre el significado de lo que está pasando. Pero a la hora de entrevistarle, y de aparecer esa foto, automáticamente el informante relata la historia "Estábamos mis colegas y yo un viernes por la tarde y nos paró la urbana (policía), Rober llevaba chocolate y lo tiró a una alcantarilla. Aquí estamos intentando cogerlo, pero no pudo ser. Da igual, sólo era una chinilla" (un trozo pequeño, que llega para liarse un solo porro). Cuando le pregunté por qué había hecho la foto, me contestó "porque lo estábamos pasando bien, y así me reía un rato del Rober".

Se trataba de observar qué momentos eran importantes y, por ello, dignos de ser inmortalizados. Buxó describe de esta manera la técnica de la elicitación fotográfica:

Exploración conjunta para reconstruir la experiencia cultural sobre la base del diálogo, los recuerdos e incluso mediante el intercambio de objetos de amplia vocación visual (Buxó: 1999: 6).

De esta manera, la estructura de la entrevista consistía en mostrar las fotografías, que me explicaran dónde la habían tomado, qué estaba pasando en ellas y por qué habían elegido ese momento exacto. Me ceñí en todo momento este guión, siempre teniendo como referente las imágenes. Cuando la interpretación de una imagen se agotaba, o el informante se iba por las ramas, pasábamos a la siguiente. En ocasiones utilizamos también las fotografías de los móviles, imágenes de familia (uno de los entrevistados trajo unas cuantas de su casa), o en Internet, pero la principal fuente de información eran las fotografías tomadas durante los tres meses que duró el taller, ya fuera en las sesiones, o durante la semana.

La fotografía ha sido utilizada en este proyecto como manera de analizar el universo visual de estos adolescentes y como estrategia para crear nexos de unión entre sus imágenes, sus pensamientos y las interpretaciones que he establecido sobre ellos. Tal como nuestros amigos nos invitan a casa para enseñarnos las fotografías que han tomado durante sus viajes (ardua prueba de la amistad), mi intención era crear en las entrevistas un ambiente de confidencialidad que girara en torno a las imágenes que ellos habían decidido tomar, y que nos permitiera 


\section{perifèria}

Número 9, diciembre 2008

www.periferia. name

estructurar un discurso en torno a ellas. Tal como expresan Collier y Collier,

Las fotografías pueden ser puentes de comunicación entre extraños que devienen caminos hacia lo desconocido, los contextos extraños y los sujetos. El carácter informal del imaginario fotográfico hace posible este proceso. Pueden funcionar como puntos de partida y referencia sobre lo familiar o lo desconocido (1986: 99).

En alguna entrevista se dio el hecho de que fotografías que no estaban ahí, físicamente, salían a la luz. Por ejemplo, al preguntarle a un informante por qué no había hecho más fotografías, me explicó que muchas las había borrado porque pensaba que podrían llegar de alguna manera a manos de sus padres, o de los profesores. Le explicaba que eso no sería así y le pedía que me explicara qué había fotografiado. Esas descripciones suponían alcanzar el mismo propósito que con una fotografía que sí estaba allí y realmente no importaba que la foto estuviese "físicamente" en mi ordenador. El las imaginaba, con lo que activaba el "proceso de producir y experimentar imágenes en estado de consciencia" (Buxó, 1999: 17), que es la definición del término imaginación. También el hecho de que la hubiese borrado hace referencia al uso tradicional de la fotografía como prueba explícita de que lo que allí se ve, está sucediendo tal como parece. La imagen en general (en movimiento o fija) tiene la característica de ser aceptada por nuestros sentidos, de transferir la información que aparece como real y como prueba de que eso está sucediendo. Por ello el informante temía cuál sería el uso posterior de esas imágenes. No quería que las fotografías en que estaban fumando porros llegasen a su madre y por ello las borró. Aunque finalmente, a través de la relación que establecimos, un día acabó trayéndome una fotografía que anteriormente habría borrado y me dijo "pero cuando la hayas mirado la borras, ¿eh? Prométemelo". Estos momentos, que pueden parecer anecdóticos, me ofrecían la certeza de que la fotografía es un elemento ante el cual establecemos discursos y del que hacemos uso en determinados momentos.

Al fin y al cabo, la pregunta esencial en este apartado es ¿por qué hacer entrevistas si ya he obtenido el material fotográfico? Pues porque, como expresa Duff (nombrado en Buxó, 1999) las fotografías pueden aparecer como evidencias por sí mismas, pero cuando se trata de investigaciones cualitativas, su interpretación está 


\section{perifèria}

Número 9, diciembre 2008

www.periferia.name

abierta, y para que tengan sentido, es necesario ponerlas en conexión con otras fotografías, o con un discurso. Las imágenes son fácilmente manipulables, al igual que el texto. La diferencia principal, es que la fotografía fija un momento que es captado por nuestros sentidos y el texto es más flexible, en el sentido de incluir conceptos que abren múltiples campos de significado y que en ocasiones están vetados a los que no son expertos en el tema tratado. En este sentido, podemos decir que la fotografía contiene un lenguaje entendido por todos, a partir del cual establecer discursos e interpretaciones variados.

En estas entrevistas he tenido que replantear el método, por el hecho de estar tratando con adolescentes. ¿Cómo entender el discurso implícito en sus palabras? ¿Cómo interpretar afirmaciones que sabes exactamente que forman parte de su imaginación? ¿Sus afirmaciones se basan en el ser, o en el desear ser? Nunca antes había entrevistado a personas de esta edad, y un principio me planteé si serían informantes válidos, por el hecho de encontrarse éstos en un momento de conflicto identitario, de crecimiento y desarrollo de un "yo" estrechamente unido al grupo de iguales. Después de haber conocido trabajos que sí se desarrollan con adolescentes (por ejemplo, los de Carles Feixa o Laura Porzio), entendí que podían realizarse, pero que había que buscar otras estrategias diferentes a las que había aprendido en las entrevistas realizadas anteriormente. En estas entrevistas me interesaba también contrastar sus comportamientos y discursos individuales, frente a los de grupo, que observaba en cada sesión conjunta.

Pasaré a continuación a explicar los primeros resultados obtenidos a través de esta metodología, que dejan abierta la puerta a análisis posteriores, con los que pretendo extraer explicaciones a los aspectos representativos observados en el comportamiento del grupo estudiado. 


\section{perifèria}

Número 9, diciembre 2008

www.periferia.name

\section{La UEC: el microcosmos y la estructura compleja}

Paul Willis, en su conocido libro ${ }^{14}$, analiza la cultura contraescolar de un grupo de jóvenes de clase obrera, en Inglaterra, como manera de entender los mecanismos de reproducción social que llevan a éstos a socializarse de tal manera en el ámbito escolar que salen del centro educativo sin graduarse y comienzan a trabajar manualmente de manera inmediata al llegar a la edad máxima de escolarización. Este ha sido un texto que, aunque escrito hace ya treinta años, ofrece una serie de indicios que sirven para analizar ciertos fenómenos observados durante el trabajo de campo que aquí presento. Al igual que en el trabajo de Willis, los informantes provienen de un barrio que, como hemos apuntado, fue construido en torno al crecimiento industrial y turístico de la ciudad. Son, además, chicos que presentan un fracaso escolar acentuado, y de los que no se espera que sigan un recorrido académico exitoso. Son vistos por su entorno como "carne de cañón", es decir, que nadie espera de ellos que se comporten "correctamente", sino que se tiene la expectativa de que crearán problemas a lo largo de toda su vida. En cierta manera, por las informaciones que extraje de su ámbito familiar, sus padres y familiares cercanos se encuadran en este perfil, presentando situaciones problemáticas relacionadas con los maltratos, la drogadicción, la pobreza, el abandono. Incluso dentro del grupo acudían dos chicos que eran hermanos. También otros habían tenido hermanos o familiares que en algún momento habían pasado por una UEC. ¿Cómo estudiar entonces este entorno desde un punto de vista micro, dejando atrás aspectos estructurales del análisis? ¿Cómo entender sus comportamientos, sus trayectorias vitales, sin alejarse de aquello que observamos directamente, para reflexionar sobre la violencia estructural escondida, aquella que sólo puede analizarse desde un punto de vista externo? No soy capaz de englobar todavía en categorías de análisis este tipo de violencia, pues las observaciones han sido demasiado breves como para poder hacerlo. Es común en las disciplinas de las ciencias sociales hablar de las poblaciones marginadas de manera ligera, dando por

\footnotetext{
14 1988: Aprendiendo a trabajar. Cómo los chicos de la clase obrera consiguen trabajos de clase obrera
} 


\section{perifèria}

Número 9, diciembre 2008

\section{www.periferia.name}

hecho ciertos aspectos y afirmaciones, sin haber realizado un análisis profundo ${ }^{15}$. A partir de mi trabajo en este terreno, presentaré una serie de indicios para el análisis, que se centrarán en las formas de representación de estos jóvenes, que espero sirvan para tender puentes hacia futuros análisis estructurales.

\subsection{Formas de representación}

Los grupos de adolescentes se manifiestan simbólicamente a través de un estilo propio. Es éste un sistema de comunicación, una forma de expresión y representación expresada colectivamente. En el trabajo de campo he detectado una serie de aspectos relativos a estas formas de representación, que en muchas ocasiones se han inmortalizado mediante fotografías.

Un aspecto observado durante el trabajo en grupo, y que anteriormente he apuntado, fue la clara diferenciación que los informantes establecían en los comportamientos de hombres y mujeres. Para Willis, el machismo de la cultura contraescolar refleja a nivel global la concepción que de la mujer se tiene en la clase obrera. Esto se traduce en que ha de ser sexy y provocativa, al mismo tiempo que virgen y sumisa. Las fotografías que mostraban de "sus chicas" en el móvil, seguían el patrón establecido de mujer explosiva, que se muestra ante la cámara para parecer sexy ante un público concreto, el de los chicos (sólo es necesario introducirnos en el mundo de los fotologs ${ }^{16}$ para encontrar este tipo de fotografías). Por su parte, el hombre ha de ser duro, arrogante y ha de demostrarlo a través de las peleas, los desafíos a la estructura formal. En el centro, quien no se comportaba así, era víctima de la desvalorización dentro del grupo, y corría el riesgo de colgarse la etiqueta de "pringado" o de "parguela"17. Sólo en una ocasión me hablaron de una chica a la que tenían respeto, en el sentido de que era alguien que sabía defenderse, que podía pelearse con hombres. Me hablaron de ella cuando la

\footnotetext{
${ }^{15}$ Pondremos como ejemplo el análisis del sociólogo Loïc Waquant (2007), que denuncia el uso arbitrario e interesado del término "underclass", por parte de los expertos académicos de este tipo de poblaciones y por extensión, de los medios de comunicación. En la misma línea rechaza el uso del término "gueto" para la banlieu parisina, desarrollando una teoría que la compara con el gueto negro de Chicago.

${ }^{16}$ Los fotologs son espacios en Internet en que se muestran fotografías y se comparten con otras personas. Son extensamente utilizados por personas de la edad de los informantes (adolescentes), que tienen acceso a Internet.

${ }^{17}$ Término que viene del argot gitano y que significa, vulgarmente, "maricón"
} 


\section{perifèria}

Número 9, diciembre 2008

\section{www. periferia. name}

encontramos un día, en uno de los paseos, y uno de ellos, el líder, me dijo "esa tía es chunga, es como un tío". Ser fuerte, saber defenderte, no tener miedo, son algunos de los rasgos de personalidad que ellos admiran. Escapar, no dar la cara, ser débil, tener miedo, significa "no saber vivir a tope". No hay nada peor que verse humillado en una pelea, hay que Ilegar hasta las últimas consecuencias. El grupo de iguales, de esta manera, actúa presionando a los individuos para que se comporten como "tipos duros". Siempre solía haber en las interacciones cotidianas algún tipo de violencia física, aunque fuera una manera de pasar el rato, de "jugar". Sólo en una ocasión pude ver que dos de ellos se pelearan en serio, y en ese momento el grupo se unió para separarlos, junto con las profesoras. Lo cierto es que cohabitando diariamente en un mismo espacio, este tipo de comportamiento se retroalimenta, es consensuado y validado por el grupo.

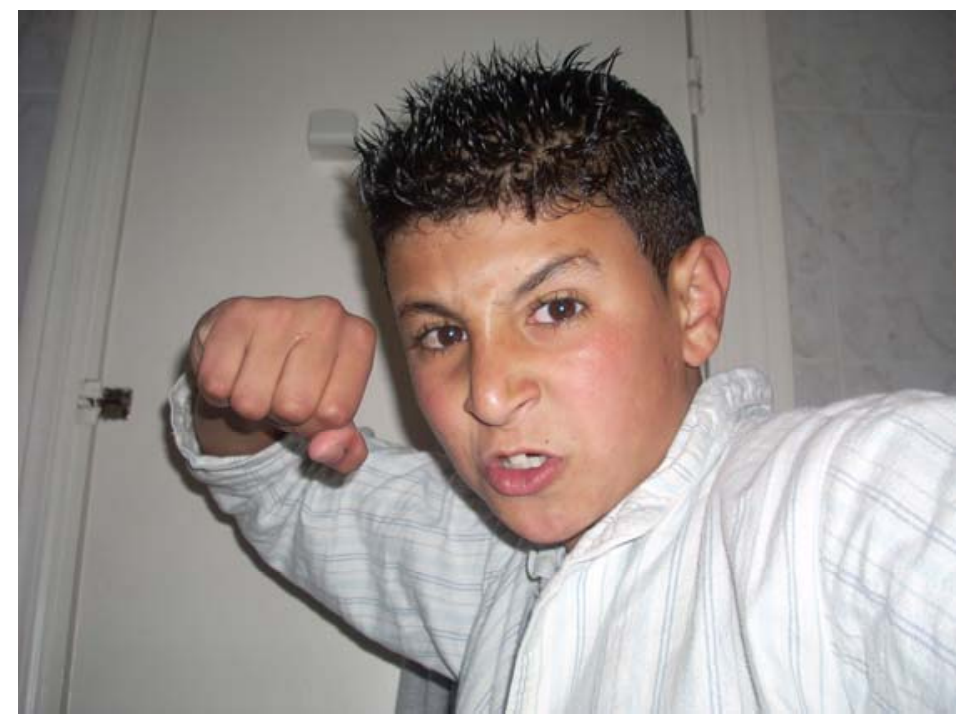

I magen 1

No olvidemos que estamos hablando de un grupo pequeño, que coexiste cotidianamente, y que va reestructurándose a partir de diferentes acontecimientos. Me he dedicado a analizar aquellos elementos que unían al grupo frente a agentes externos, superando cualquier tipo de conflicto interno, para mantenerse fuertes frente a los agentes externos. La estructura informal se representaba en el grupo 


\section{perifèria}

Número 9, diciembre 2008

www.periferia. name

de iguales y cohabitaba en tensión constante con la estructura formal. En el análisis de Willis, el grupo actúa como esfera informal de resistencia ante la estructura de lo formal (el centro escolar y las normas que rigen el funcionamiento del mismo):

La escuela es la zona de lo formal. Tiene una estructura clara: el edificio escolar, las normas escolares, el trabajo pedagógico cotidiano, la jerarquía profesoral (...). La cultura contraescolar es la zona de lo informal, en la que se rechazan las demandas incursivas de lo informal (1988 [1978]: 36)

Willis trata en profundidad el rechazo generalizado hacia la figura del profesor, por parte de todos los alumnos con los que trabajaba. No hay que olvidar que el centro que estamos tratando se encuentra separado del instituto al que se supone tienen que acudir estos alumnos. Las expulsiones provienen en muchas ocasiones de conflictos directos con los profesores del centro. Cuando le pregunté a uno de los informantes por qué había sido expulsado, me contestó lo siguiente:

Me trajeron aquí porque la liaba (...) ¿Qué hacías? Pues liarla, seño, qué voy a hacer. Al director casi lo pego, es un hijo de puta, me vacilaba todo el rato. No me callaba. Ahí en medio del pasillo, vacilándome delante de todos y chillándome allí. Tenía el deo partío, me quité la venda y todo. Le dije: "¿qué pasa ya maricón?". Es lo que hay. Me echaron por más cosas, y por tocar todos los días la alarma, y todo el mundo iba fuera...

La distribución de roles dentro del grupo, la figura clara del líder y del pringado, los ataques constantes a profesores y equipamientos escolares, los pactos intergrupales establecidos por la edad, u otras características internas, sirven para mantener unido al grupo ante las "agresiones" externas de lo formal, que en este caso se refieren a los profesores y las normas que éstos sustentan. Al encontrarse el grupo aislado en referencia a sus ex compañeros de instituto, no existe una confrontación clara con otros chicos de su edad que son considerados como "pringados" por respetar la estructura de lo formal (aquellos que respetan las normas y a los profesores, sacan buenas notas). 


\section{perifèria}

Número 9, diciembre 2008

www.periferia.name

Si alguien transgrede una norma, ha de hacer saber a los otros que lo ha hecho, porque de otra manera ¿cómo seguiría siendo entonces una violación de la norma? En un principio me sorprendió que se delataran tan fácilmente, que corrieran riesgos que seguramente acabarían en algún tipo de castigo (expulsión, llamada y reunión con los padres). En una ocasión, uno de los informantes trajo en su cámara unas fotos en que aparecía con una chica (una menor también) en actitudes sexuales explícitas. Él sabía que el hecho de enseñar estas fotos supondría algún tipo de represalia por parte de los profesores. Pero igualmente lo hizo, tras habérselo contado a todos sus compañeros. Era la prueba de que había tenido una experiencia sexual, de que era lo suficientemente hombre. Primero, para hacerlo, y segundo, para mostrar que lo había hecho, incluso a los profesores.

Además de las peleas, del sexo, estaba siempre presente el tema de las drogas. Era conocido por todos que la mayoría de ellos consumía marihuana o hachís (porros, en su jerga). En ocasiones se escapaban de las horas de clase para consumir y llegaban "fumados" o pretendían fumar en la hora del taller de fotografía (como salíamos a la calle, era lógico para ellos hacerlo). Insistían constantemente en contarte qué droga llevaban, cómo lo habían conseguido, cuándo se iban a fumar. Para ellos, consumir estas sustancias es, de nuevo, una manera de transgredir las normas, de sentir que están viviendo el máximo, arriesgando en cada momento. Muchas fotografías relacionadas con este tema llegaron durante el taller. Autorretratos fumando, imágenes de lo que habían comprado, ellos con sus amigos a punto de fumar, plantas de marihuana. En cuanto a otro tipo de drogas (cocaína, heroína) se hablaba cotidianamente de ellas pero en ningún momento se afirmaba que se hubieran consumido. 


\section{perifèria}

Número 9, diciembre 2008

www.periferia.name

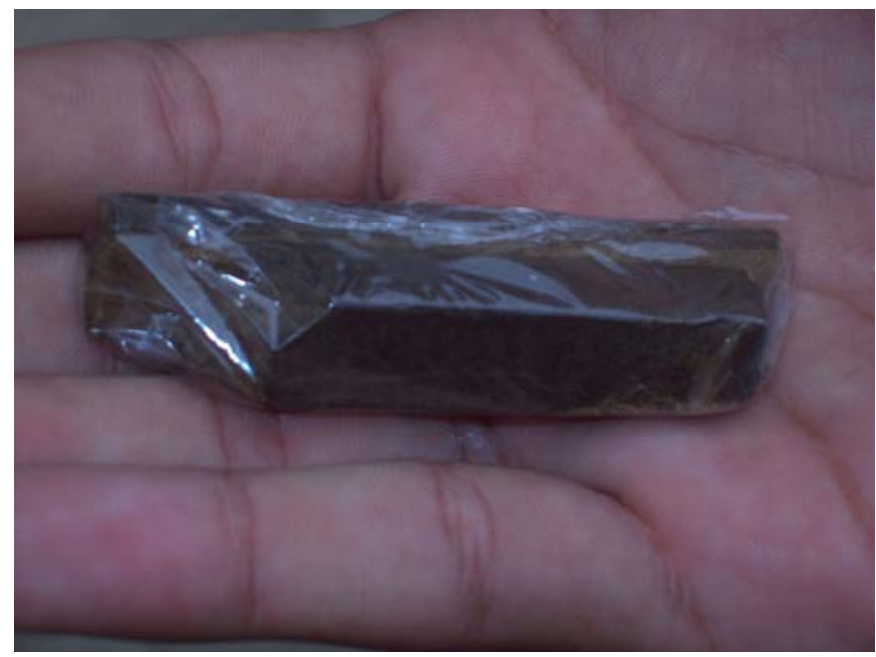

I magen 2

Otro tema que surgía cotidianamente era la música, y todo aquello asociado a ella. Era un elemento de unión, a través del cual encontré un camino para comunicarme con ellos. Me interesaba por los grupos que les gustaban, el tipo de música, la estética. El hip-hop ha sido el estilo predominante. Me parece interesante analizar la estética, las letras, los comportamientos asociados a esta música. En muchas de las canciones que he ido escuchando durante el trabajo de campo se hace una clara alusión al barrio, como territorio que forma a las personas en el arte de vivir con poco, que las hace duras, que les enseña a cuidarse. Uno de los informantes me ofreció su música para añadir en un vídeo que haríamos con sus fotos y me dijo que una de las canciones la había compuesto su primo. Insistió en recitar para la grabadora el principio de una de ellas: Huracán Bardo/ Es el gato pardo que escapó del prado/ Para vivir en la jungla de Campo Claro ${ }^{18}$. No sólo el barrio, sino también la violencia, el sexo y las drogas son temas que aparecen comúnmente en este tipo de música. La música como elemento identitario es un amplio campo de análisis que me gustaría tratar en el trabajo de campo que llevo a cabo actualmente. Para empezar, este curso, uno de los informantes ha decidido hacer como trabajo final

\footnotetext{
${ }^{18}$ Campo Claro es uno de los barrios de Ponent que mayores índices de conflicto social presenta.
} 


\section{perifèria}

Número 9, diciembre 2008

www.periferia.name

en el taller un vídeo en el que canta un rap que ha compuesto con la ayuda de los profesores. A éste añadiremos fotografías que hizo en el taller anterior, en las que aparece adoptando posturas propias de este estilo musical.

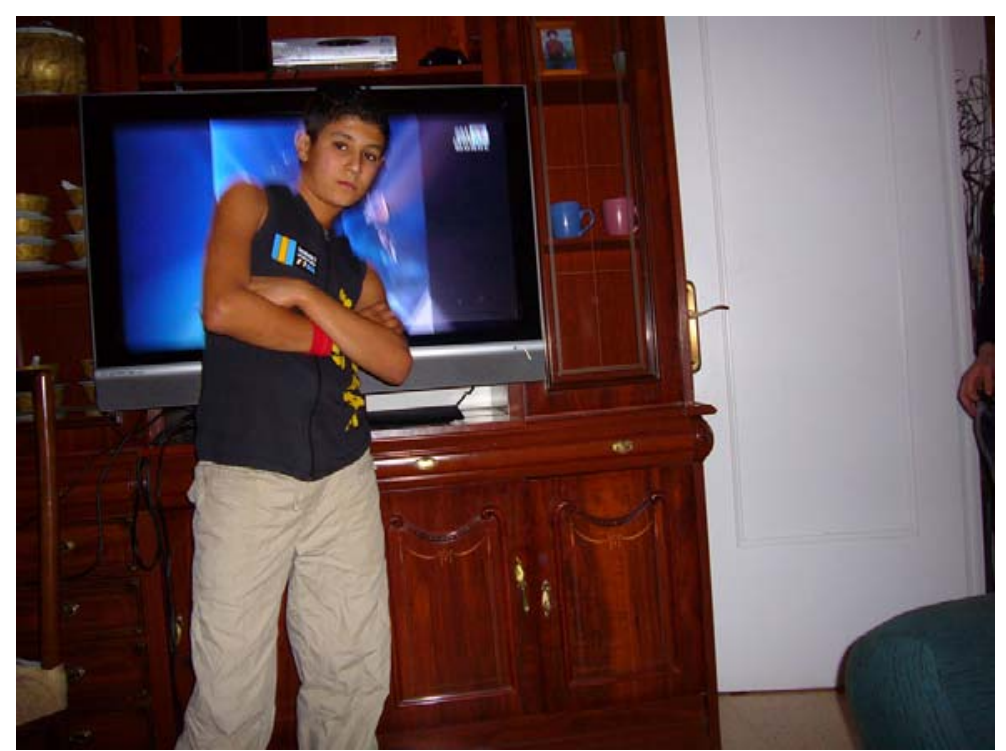

\section{I magen 3}

\section{Conclusiones}

Con estas aproximaciones al objeto de estudio he pretendido adentrarme en la cosmovisión de estos adolescentes, como manera de analizar la manera que tienen de representarse y los discursos que elaboran sobre ellos mismos y su entorno. Como apuntaba en la contextualización, podríamos decir que su situación es doblemente segregada, por pertenecer a una zona de la ciudad históricamente desfavorecida y que presenta situaciones de marginalidad, y por haber sido expulsados del sistema educativo normalizado, por ser considerados como elementos no deseados del mismo. 


\section{perifèria}

Número 9, diciembre 2008

www. periferia. name

Estos indicios que he expuesto deben ser desarrollados en el futuro para estructurar una teoría sobre la reproducción social y la segregación, y su relación con el ámbito urbano y educativo. Establecer una teoría general sobre las situaciones que viven estos adolescentes requiere de un trabajo más extenso y un análisis comparativo con otros contextos urbanos y educativos. La pregunta principal se plantea desde el punto de vista de la reproducción social de la desigualdad, ¿por qué estos adolescentes están de partida predestinados al fracaso escolar, a los trabajos manuales, a la delincuencia?

Mi convicción, y la línea en que trabajaré los futuros análisis, es que las situaciones que viven estas personas no pueden ser observadas a la luz de conductas individuales, sino como consecuencia de un engranaje mucho más extenso que requiere de un punto de vista a nivel global y comparativo, para entender la violencia estructural que se ejerce en las sociedades contemporáneas sobre determinadas poblaciones y las causas y consecuencias de la misma.

\section{Bibliografía}

Buxó, Mạ J: “...que mil palabras”. En: Buxó, Mạ J y De miguel, J (Eds.) (1999). De la investigación audiovisual. Fotografía, cine, televisión. Proyecto'a, Barcelona, pp. 1-23.

Collier, J \& Collier, M (1986). Visual Anthropology. Photography as a Research Method. University of New Mexico Press.

Edwards, E (1992). Anthropology and Photography. Royal Anthropological Institute, London.

Edwards, E: Beyond the boundary: a consideration of the expressive in photography and anthropology in: Banks, Marcus \& Morphy, H (ed.)(1999). Visual Anthropology Rethinking. Yale University Press London: pp 53-79.

Pujadas, J; Bardají, F (1987). Los barrios de Tarragona. Una aproximación antropológica. Ajuntament de Tarragona, Área de Relacions Ciutadanes. 


\section{perifèria}

Número 9, diciembre 2008

www. periferia. name

Taylor, S.J y Bogdan, R (1992). Introducción a los métodos cualitativos de investigación. Ediciones Paidós I bérica, Barcelona.

Wacquant, L (2007). Los condenados de la ciudad. Gueto, periferias y Estado. Siglo XXI Editores Argentina.

Willis, P (1988 [1978]). Aprendiendo a trabajar. Cómo los chicos de la clase obrera consiguen trabajos de clase obrera. Ediciones Akal, Madrid. 